\title{
Author Correction: Targeted exon skipping with AAV-mediated split adenine base editors
}

Jackson Winter ${ }^{1}$, Alan Luu ${ }^{2,3}$, Michael Gapinske ${ }^{1}$, Sony Manandhar', Shraddha Shirguppe ${ }^{1}$, Wendy S. Woods ${ }^{1}$, Jun S. Song ${ }^{2,3}$ and Pablo Perez-Pinera ${ }^{1,3,4,5}$

\section{Correction to: Cell Discovery (2019) 5:41 https://doi.org/10.1038/s41421-019-0109-7, Published online 20 August 2019}

In the original publication of this article ${ }^{1}$, Fig. 4 was labelled incorrectly. The second panel displaying HSF1 Exon 10 should be labelled as HSF1 Exon 11, while the third panel displaying JUP Exon 11 should be labelled as $J U P$ Exon 10. The same labelling change should be applied to the corresponding panels in Fig. 5, as HSF1 Exon 10 and JUP Exon 11 were incorrectly labelled in that figure as well and should be replaced with HSF1 Exon 11 and JUP Exon 10, respectively.
All instances of HSF1 exon 10 within the text should be corrected to HSF1 exon 11 and all instances of JUP exon 11 should be corrected to JUP exon 10 .

Published online: 15 October 2019

\section{References}

1. Winter, J., Luu, A., Gapinske, M., Manandhar, S., Shirguppe, S., Woods, W.S. Song, J.S. \& Perez-Pinera, P. Targeted exon skipping with AAV-mediated split adenine base editors. Cell Discov. 5, 41 (2019).

Correspondence: Pablo Perez-Pinera (pablo@illinois.edu)

'Department of Bioengineering, University of Illinois at Urbana-Champaign, Urbana, IL 61801, USA

${ }^{2}$ Department of Physics, University of Illinois at Urbana-Champaign, Urbana, IL 61801, USA

${ }^{3}$ Carl R. Woese Institute for Genomic Biology, University of Illinois at UrbanaChampaign, Urbana, IL 61801, USA

${ }^{4}$ Carle Illinois College of Medicine, Champaign, IL 61820, USA

${ }^{5}$ Cancer Center at Illinois, University of Illinois at Urbana-Champaign, Urbana, IL 61801, USA

() The Author(s) 2019

(c) (i) Open Access This article is licensed under a Creative Commons Attribution 4.0 International License, which permits use, sharing, adaptation, distribution and reproduction in any medium or format, as long as you give appropriate credit to the original author(s) and the source, provide a link to the Creative Commons license, and indicate if changes were made. The images or other third party material in this article are included in the article's Creative Commons license, unless indicated otherwise in a credit line to the material. If material is not included in the article's Creative Commons license and your intended use is not permitted by statutory regulation or exceeds the permitted use, you will need to obtain permission directly from the copyright holder. To view a copy of this license, visit http://creativecommons.org/licenses/by/4.0/. 

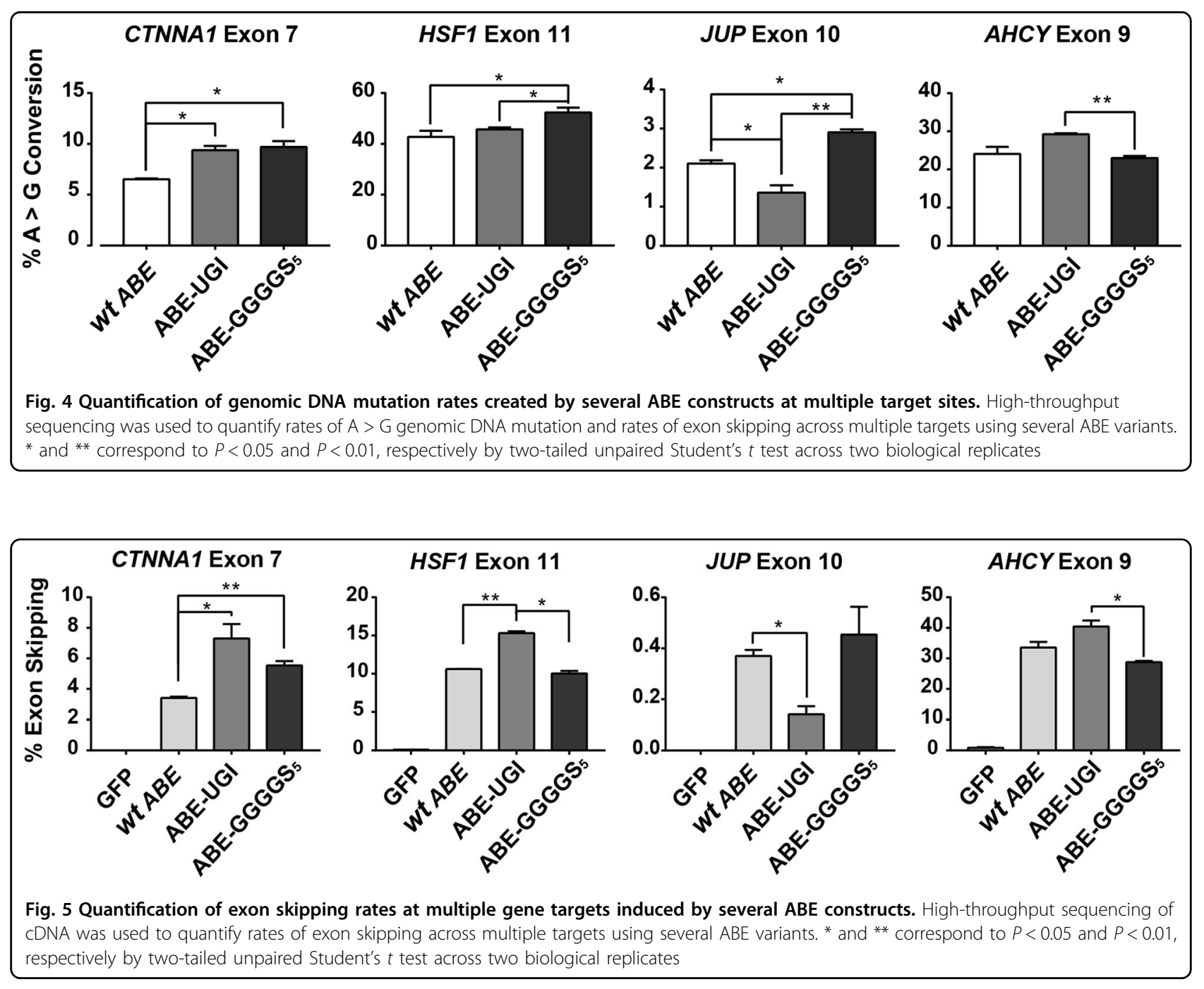